\title{
Some ecological implications of Agaricomycete phenology
}

\section{Halbwachs H}

Bavarian Forest National Park, Danziger Str. 20, D-63916 Amorbach, Germany

Halbwachs H 2018 - Some ecological implications of Agaricomycete phenology. Asian Journal of Mycology 1(1), 114-120, Doi 10.5943/ajom/1/1/9

\begin{abstract}
Macrofungi, and specifically Agaricomycetes, are important drivers for nutrient partitioning and cyling in terrestrial ecosystems and other ecosystem processes. Fruiting patterns of saprotrophic and ectomycorrhizal taxa bear implications for the maintenance of fungal assemblages that interact with their environment. While fruiting patterns have been investigated in a few cases, biome-wide studies across a comprehensive number of Agaricomycete species with a special focus on their temporal ecology, are lacking. Based on a of more than 2000 ectomycorrhizal and saprotrophic Agaricomycetes, the phenologies of both guilds have been investigated. The phenologies of either guilds coincide to a large extent. Surprisingly, the course of fruiting is bimodal, i.e. showing minima in spring, July and autumn. Possible explanations, in particular avoidance of fungivores and of evading activities of competing microorganisms are discussed.
\end{abstract}

Key words - mushrooms - fruiting - longevity - dispersal - invertebrates - fungivores - vectors life history strategy - competition - trade-off

\section{Introduction}

Macrofungi, and specifically Agaricomycetes, are important drivers for nutrient partitioning and cyling in terrestrial ecosystems and other ecosystem processes (Trappe \& Luoma 1992). During their life cycle, the development of fruit bodies is crucial for reproduction and dispersal (Dix \& Webster 1995), i.e. for the maintenance of fungal assemblages that interact with their environment. Among other traits, temporal patterns of fruiting (phenology) may be of ecological relevance because it is often part of assembly rules (Morin 2011). Fruit bodies are, for example, important nutrient sources for micro- and macrofauna (Straatsma et al. 2001), and temporal correlations are likely to contribute to the functioning of food webs.

While the timing of fruit body production is commonly triggered by precipitation, temperature and nutrient availability (Moore et al. 2008, Boddy et al. 2014), a good part of the phenology of Agaricomycetes is genetically controlled (Selosse et al. 2001). Most species in temperate to boreal biomes seem to fructify towards autumn, some already in early spring (Boddy et al. 2014). There are indications that ectomycorrhizal taxa fructify during a narrower time range towards the end of a year than saprotrophs (Khasa et al. 2009). Typical spring, summer and autumn fruiters are shown in Fig. 1.

To further clarify the ecological implications of differences in fruiting phenologies, more data on fruiting patterns across a wider taxonomical and ecozonal range are needed. I therefore compiled and analysed a database of Agaricomycetes, and interpreted the results with respect to fungal life strategies, trophic modes and interactions with associated invertebrates. 


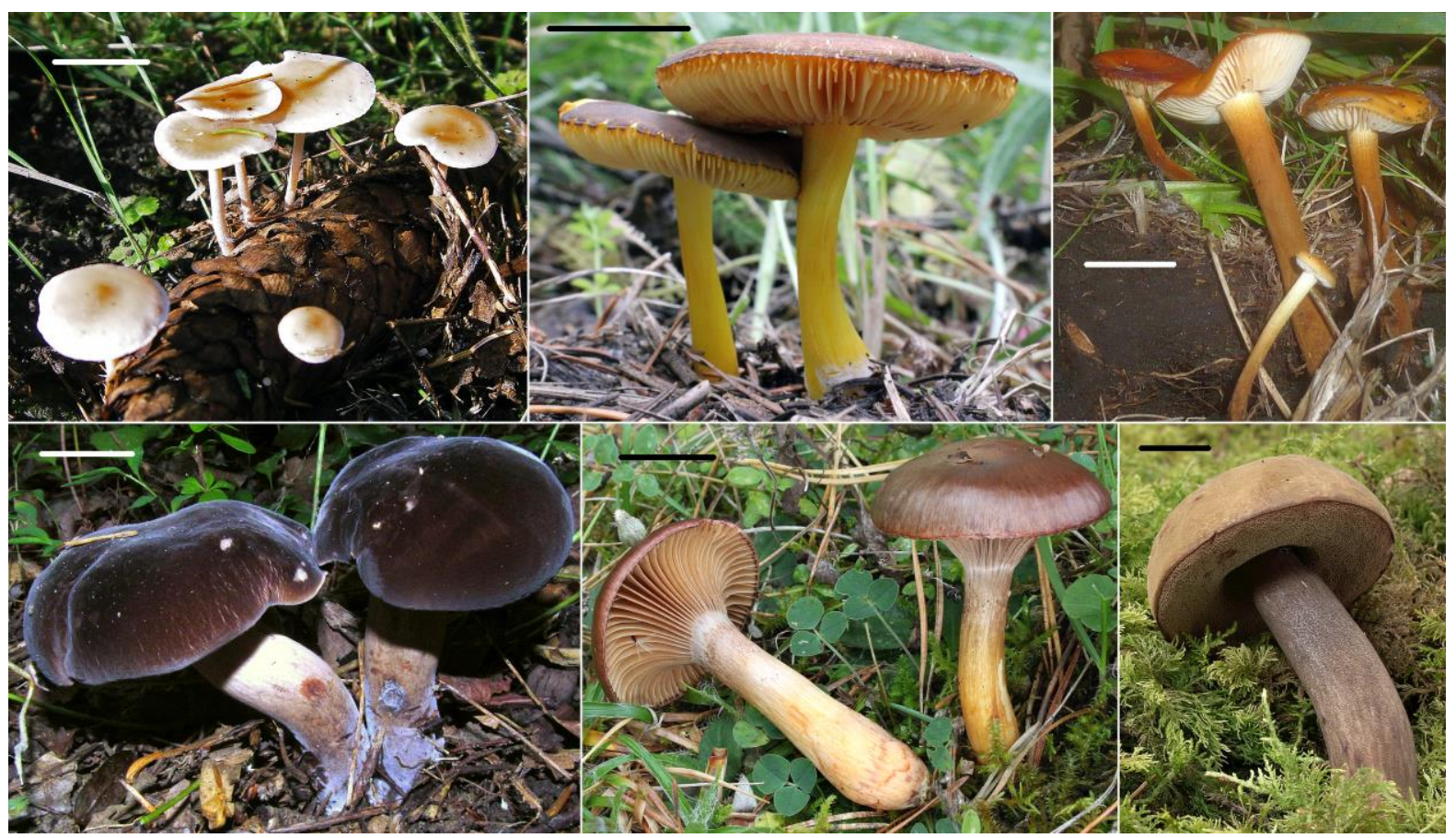

Fig. 1 - Top row - Saprotrophic: Strobilurus esculentus (Wulfen) Singer (Image Thomas Pruß (cc)), Pluteus romellii (Britzelm.) Sacc. (Image Landsnorkler (cc)), Flammulina ononidis Arnolds (Image Gerhard Koller (cc)). Bottom row - Ectomycorrhizal: Tylopilus alboater (Schwein.) Murrill (Image Martin Livezey (cc)), Chroogomphus rutilus (Schaeff.) O.K. Mill. (Image H. Krisp (cc)), Porphyrellus porphyrosporus (Fr. \& Hök) E.-J. Gilbert (Image A. Kunze (cc)); size bars $2 \mathrm{~cm}$

\section{Materials \& Methods}

A compilation of 1026 ectomycorrhizal and 1262 saprotrophic mushroom phenological information extracted from the Funga Nordica (Knudsen \& Vesterholt 2012) served as a database. By using only one source, the integrity of data was ensured. The phenological information was converted to months (Table 1).

Table 1 Matching seasonal information with months based on the Funga Nordica

\begin{tabular}{lll}
\hline Season & Days & Month \\
\hline Early spring & 87.5 & II \\
Spring & 112.5 & III \\
Late spring & 137.5 & IV \\
Early summer & 166.7 & V \\
Summer & 198.0 & VI \\
Late summer & 229.3 & VII \\
Early autumn & 258.3 & VIII \\
Autumn & 283.0 & IX \\
Late autumn & 307.7 & X \\
Early winter & 350.5 & XI \\
Winter & 409.5 & XII \\
\hline
\end{tabular}

To visualize the fruiting patterns of the ectomycorrhizal and the saprotrophic guild during the seasons, species numbers per fruiting month were plotted as a bar chart.

To elucidate the species distribution of both guilds along the annual seasons, a t-test was applied, and basic statistical parameters were calculated using PAST version 3.21 (Hammer et al. 2001). 
To show phenological differences among the genera, mean fruiting months of all species of each taxon were calculated.

To show phylogenetic patterns, the phenological data of the genera were aggregated to the next higher taxonomic and assigned to the respective branches of the current phylogenetic tree weighted by species means (Hibbett 2007).

\section{Results}

Ectomycorrhizal and saprotrophic taxa show differing bi-modal fruiting patterns (Fig. 2).

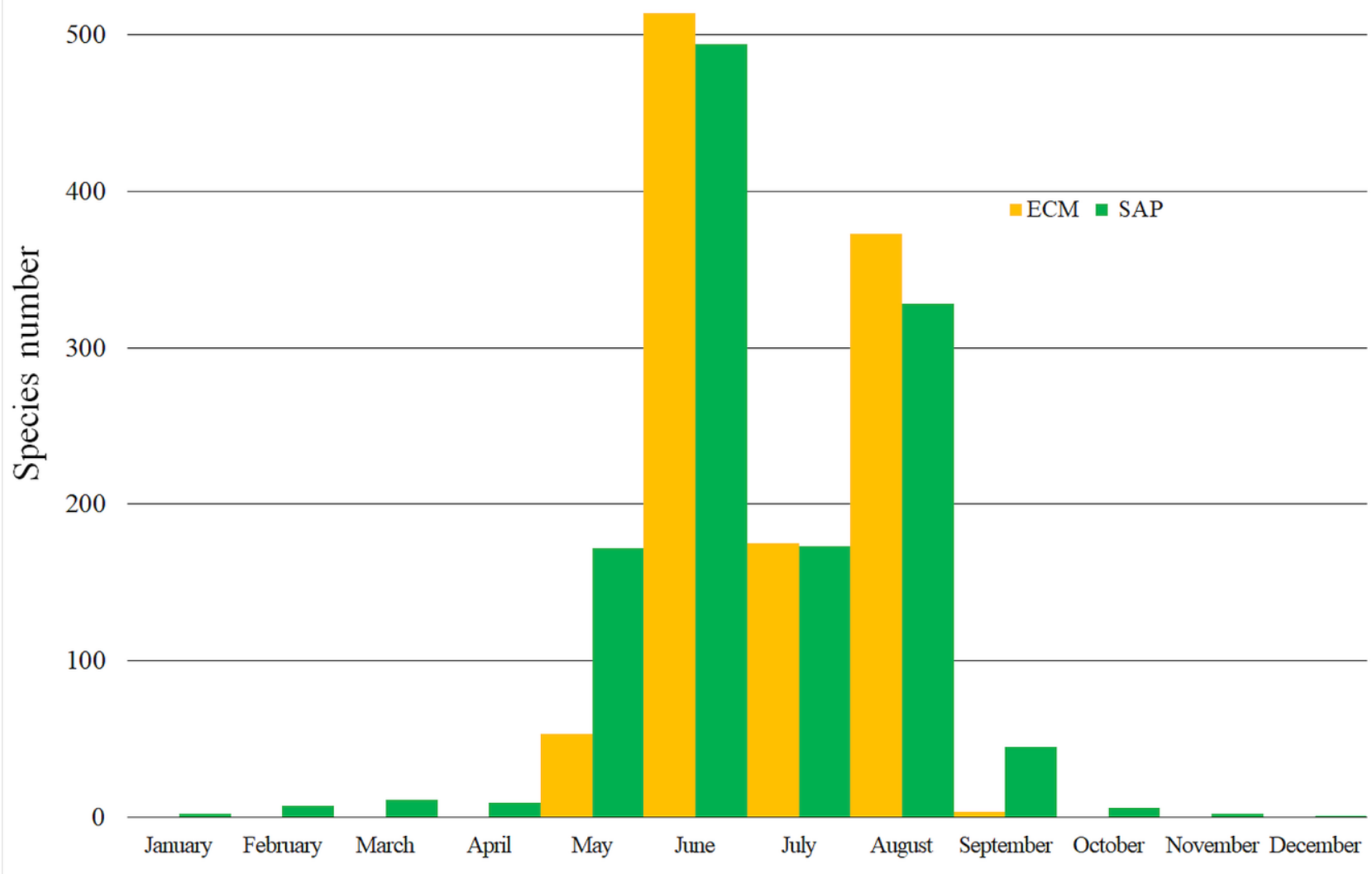

Fig. 2 - Comparison of the numbers of the ectomycorrhizal (orange) and saprotrophic (green) species during a year.

The t-test came up with a probability of $\mathrm{p}=0.14$ (Monte Carlo) for equal means. The statistical results are shown in Table 2.

Table 2 Comparison of mean saprotrophic (SAP) and ectomycorrhizal species fruiting months by basic statistical parameters

\begin{tabular}{llllll}
\hline & Sample size & Mean & Standard error & Median & Skewness \\
\hline SAP & 1263 & 6.8 & 0.038 & 6.5 & 1.38 \\
ECM & 1026 & 6.9 & 0.026 & 6.5 & -0.23 \\
\hline
\end{tabular}

The fruiting patterns for all Agaricomycete genera in the data set are presented in Tables S1, S2. The compilation of phylogenetic phenology patterns largely revealed close similarities among the clades (Fig. S1).

See supporting material: https://osf.io/dzu4n/?view_only=1dbbc66a805445d48b027ee8a594807f 


\section{Discussion}

Compared to the ectomycorrhizal species, the saprotrophic species show a wider temporal fruiting range, even though in both guilds the fruiting peaks coincide (Fig. 2, Table 2). The more compressed fruiting season of the ectomycorrhizal guild is probably controlled by species-specific cues of the hosts (Dickie et al. 2010, Kauserud et al. 2012) in connection with carbon (photosynthate) availability (Sato et al. 2012). This holds true even for taxa that exhibit saprotrophic capacities (Lindahl \& Tunlid 2015), e.g. Cortinarius because they degrade soil organic compounds predominantly to capture nutrients other than carbon (Hupperts et al. 2017).

There are indications that primary production and precipitation are drivers for early fruiting ectomycorrhizal species, while temperature drives fruiting of early saprotrophic and late saprotrophic as well as late ectomycorrhizal taxa (Andrew et al. 2018). Generally, early colonisers among saprotrophic taxa (r-selected, e.g. Strobilurus, see Table S1) fruit more proficiently and are smaller than K- or S-selected late fruiters (Boddy et al. 2014). Moreover, late fruiters are rarer than early appearing mushrooms (Simmel \& Poschlod 2017)

Clade-related fruiting patterns generally do not show conspicuous clustering, perhaps with the exception of the agaricoid clade which has the broadest range of three months. The latter may be explained by the high proportion of species in the data set (Table 3 ).

Table 3 Phenology range and species number of the clades investigated

\begin{tabular}{lll}
\hline Clade & Phenology & Species no. \\
\hline Agaricoid & July-September & 1180 \\
Tricholomatoid & July-August & 664 \\
Marasmioid & August & 105 \\
Amanitaceae & September & 37 \\
Pluteoid & August & 39 \\
Hygrophoroid & August & 48 \\
Incertae sedis & August & 24 \\
Boletales & August-September & 83 \\
Russulales & August-September & 248 \\
Polyporales & August & 3 \\
\hline
\end{tabular}

Phylogenetic patterns and the seasonal fruiting distribution of both ectomycorrhizal and saprotrophic taxa point at common drivers. Generally, sufficient precipitation is a precondition for developing fruit bodies (Chacón \& Guzmán 1995, Pinna et al. 2010), while the course of temperature controls the timing (Straatsma et al. 2001). This is corroborated by the effect of climate change (warming!) which leads to shifts in fruiting seasons across a large number of taxa (Kauserud et al. 2008, Büntgen et al. 2011, Kauserud et al. 2012, Boddy et al. 2014).

At an individual level, fruiting is commonly triggered by disturbances, for example when mycelia reach substrate edges, nutrients become depleted or injured (Moore et al. 2008). Another common fruiting stimulator is cold-shock, i.e. a sharp temperature drop below a certain threshold over a certain period of time (Pinna et al. 2010).

On the other hand, genetic factors may modulate patterns induced by weather and climate. It is, for instance, striking that fungal and insect fungivore phenologies only marginally overlap. In Greenland, fungal fruiting peaks around July/August (Petersen 1977), while Mycetophilidae and Muscidae in Greenland and Arctic Canada, both taxa being predominantly fungivores, have their peak season about one month earlier (Høye \& Forchhammer 2008, Bolduc et al. 2013) with an overlap of ca. two weeks. This suggests that the fungi have adapted to avoiding damage by insect fungivores (Hanski 1989, Boddy \& Jones 2008). On the other hand, entirely avoiding associated insects could lead to a critical impoverishment of vectors. Insects are supposed to be important 
dispersers, particularly for ectomycorrhizal taxa (Halbwachs \& Bässler 2015). Therefore, the overlap between fungal and insect fungivore phenologies in the Arctic could be a trade-off between damage and dispersal. In this context, it should be noted that species with larger fruit bodies withstand destruction longer than smaller ones (Hanski 1989). However, global warming leads to shifts in mushroom fruiting (Boddy et al. 2014) which could disrupt, e.g. interactions with animals. It remains to be seen if the phenotypic and genotypic plasticity of all interacting organisms can counteract detrimental effects. In this vein, phenotypic variance may be induced by hosts (Dickie et al. 2010), and genetically-based phenology shifts as observed in Laccaria bicolor (Selosse et al. 2001).

The surprising result that fruiting of both guilds follows a bi-modal course is, at first glance, suggestive of common environmental drivers. However, typical temperature and precipitation patterns in Scandinavia do not fit the main fungal fruiting seasons in June and August. Highest long-term precipitation and temperature values occur in most Scandinavian areas during July (Diebel et al. 2018). Another possibility of the bimodal fruiting could be avoidance of the peak activity of fungivorous insects. Insect activity is temporally constricted in boreal settings, mainly driven by temperature and day length (Danks \& Foottit 1989), but only a few relevant studies on fungivorous insects are available (Põldmaa et al. 2015). Some are suggestive of asynchronous phenologies (e.g. Shorrocks \& Charlesworth 1980), others not (e.g. Bechev 2000). In this vein, it has been observed that Leccinum albostipitatum, when already fruiting in July, becomes infested by fungus gnats (Holmberg \& Marklund 2018). It appears that the phenology of mushroom-associated flying insects underlies multiple influences of the abiotic and biotic environment (Danks \& Foottit 1989), and not intrinsic factors as host-specificity (Koskinen et al. 2018). Moreover, when looking at soil-dwelling fungivores, such as epigeic Collembola (Hanski 1989), a temporal connection to fungal fruiting seems to be unlikely, because Collembola abundance is highest towards autumn (Turnbull 2014). Furthermore, mammals, as important fungivores and vectors (Halbwachs et al. 2016), do not show marked seasonal feeding habits, at least during the vegetation period.

There might be another (additional) explanation. Soil-dwelling microbiota, such as bacteria and soil microfungi compete for the ephemeral soil nutrient sources, especially during the summer. Also, some hypogeic fungivores (Collembola, Acari and Enchytraeidae) are active particularly around July (Burges \& Raw 1967). Could it be that the mycelia of mushrooms undergo a diapause during July?

Beyond all these speculations, the bimodal fruiting pattern of mushrooms and its adaptive relevance remains an enigma.

\section{Conclusion}

The ectomycorrhizal and saprotrophic guild show similar bimodal phenologies which points at substantial environmental effects, particularly temperature and moisture. The narrower fruiting band of ectomycorrhizal taxa is probably induced by host cues in connection with photosynthate production. The generally adaptive character of temporal fruiting patterns is underscored by the fact that at cladistic levels deeper than genera fruiting periods hardly differ.

Early fruiters among the saprotrophic mushrooms seem to utilise litter accumulated during the preceding cold season (temporal resource partitioning, thus minimising competition, Morin 2011) which suggests an R-selected lifestyle, while S-selected late fruiters need to cope with cold stress.

The conspicuous bimodal course of fructification may be an adaptation to peak activities of fungivores and/or competing soil microorganisms, though relating data are somewhat inconsistent. This phenomenon deserves further studies that dig deeper into the phenologies of epigeic and hypogeic invertebrates associated with mushrooms and into seasonal mycelial dynamics of mushrooms. 


\section{Acknowledgements}

My thanks go to Claus Bässler (Grafenau) for his advice concerning the interpretation of the statistical data, and to Josef Simmel (Regensburg) for his valuable comments.

\section{Accessibility of data}

The database compiled for this study can be accessed in Tables S3, S4

(https://osf.io/dzu4n/?view_only=1dbbc66a805445d48b027ee8a594807f)

\section{References}

Andrew C, Heegaard E, Høiland K, Senn-Irlet B et al. 2018 - Explaining European fungal fruiting phenology with climate variability. Ecology 99, 1306-1315.

Bechev D. 2000 - Seasonal activity and vertical distribution of fungus gnats (Diptera: Sciaroidea, excluding Sciaridae) in the western and the central parts of Stara Planina ridge (Bulgaria). Travaux Scientifiques d'Universite de Plovdiv, Animalia 36, 51-66.

Boddy L, Büntgen U, Egli S, Gange AC et al. 2014 - Climate variation effects on fungal fruiting. Fungal Ecology 10, 20-33.

Boddy L, Jones TH. 2008 - Interactions between basidiomycota and invertebrates. In: Boddy L, Frankland JC, van West P. Ecology of saprotrophic basidiomycetes. - Elsevier, 155-179.

Bolduc E, Casajus N, Legagneux P, McKinnon L et al. 2013 - Terrestrial arthropod abundance and phenology in the Canadian Arctic: modelling resource availability for Arctic-nesting insectivorous birds. The Canadian Entomologist 145, 155-170.

Büntgen U, Kauserud H, Egli S. 2011 - Linking climate variability to mushroom productivity and phenology. Frontiers in Ecology and the Environment 10, 14-19.

Burges A, Raw F. 1967 - Soil biology. Academic Press, London.

Chacón S, Guzmán G. 1995 - Observations on the phenology of ten fungal species in the subtropical forests at Xalapa, Mexico. Mycological Research 99, 54-56.

Danks H, Foottit R. 1989 - Insects of the boreal zone of Canada. The Canadian Entomologist 12, 625-690.

Dickie IA, Kałucka I, Stasińska M, Oleksyn J. 2010 - Plant host drives fungal phenology. Fungal Ecology 3, 311-315.

Diebel J, Norda J, Kretchmer O. 2018 - Weather Spark. https://weatherspark.com/ (accessed November 2018).

Dix NJ, Webster J. 1995 - Fungal Ecology. Chapman and Hall, London, 560 pp.

Halbwachs H, Bässler C. 2015 - Gone with the wind - a review on basidiospores of lamellate agarics. Mycosphere 6, 78-112.

Halbwachs H, Simmel J, Bässler C. 2016 - Tales and mysteries of fungal fruiting: How morphological and physiological traits affect a pileate lifestyle. Fungal Biology Reviews 30(2), 36-61.

Hammer Ø, Harper DAT, Ryan PD. 2001 - PAST: Paleontological statistics software package for education and data analysis (folk.uio.no/ohammer/past). Palaeontologia Electronica 4(1), 911 .

Hanski I. 1989 - Fungivory: fungi, insects and ecology. In: Wilding N, Collins NM, Hammond PM, Webber JF. Insect-fungus interactions. Academic Press, London., 25-68.

Hibbett D. 2007 - Agaricomycetes. Mushroom-Forming Fungi. Version 20 April 2007, The Tree of Life Web Project, http://tolweb.org/. From http://tolweb.org/Agaricomycetes/20535/2007.04.20.

Holmberg P, Marklund H. 2018 - Handbuch Pilze. Stiftung Warentest, Berlin.

Høye TT, Forchhammer MC. 2008 - Phenology of high-arctic arthropods: effects of climate on spatial, seasonal, and inter-annual variation. Advances in ecological research 40, 299-324. 
Hupperts SF, Karst J, Pritsch K, Landhäusser SM. 2017 - Host phenology and potential saprotrophism of ectomycorrhizal fungi in the boreal forest. Functional ecology 31(1), 116126.

Kauserud H, Heegaard E, Büntgen U, Halvorsen R et al. 2012 - Warming-induced shift in European mushroom fruiting phenology. Proceedings of the National Academy of Sciences 109(36), 14488-14493.

Kauserud H, Stige LC, Vik JO, Økland RH, Høiland K, Stenseth NC. 2008 - Mushroom fruiting and climate change. Proceedings of the National Academy of Sciences of the USA 105, 3811-3814.

Khasa D, Piché Y, Coughlan AP. 2009 - Advances in Mycorrhizal Science and Technology. NRC Research Press.

Knudsen H, Vesterholt J. 2012 - Funga Nordica: Agaricoid, boletoid, clavaroid, cyphelloid and gastroid genera. Nordsvamp, Copenhagen.

Koskinen J, Roslin T, Nyman T, Abrego N, Michell C, Vesterinen EJ. 2018 - Finding flies in the mushroom soup: Host specificity of fungus-associated communities revisited with a novel molecular method. Molecular ecology.

Lindahl BD, Tunlid A. 2015 - Ectomycorrhizal fungi - potential organic matter decomposers, yet not saprotrophs. New Phytologist 205(4), 1443-1447.

Moore D, Gange AC, Gange EG, Boddy L. 2008 - Fruit bodies: their production and development in relation to environment. In: Boddy L, Frankland J, West Pv. Ecology of saprotrophic basidiomycetes. - Elsevier - Academic Press, London, 79-103.

Morin PJ. 2011 - Community Ecology. Wiley-Blackwell.

Petersen P. 1977 - Investigations on the ecology and phenology of the macromycetes in the Arctic. Meddelelser on Grønland 199(5), 1-72.

Pinna S, Gévry MF, Côté M, Sirois L. 2010 - Factors influencing fructification phenology of edible mushrooms in a boreal mixed forest of Eastern Canada. Forest ecology and management 260(3), 294-301.

Põldmaa K, Jürgenstein S, Bahram M, Teder T, Kurina O. 2015 - Host diversity and trophic status as determinants of species richness and community composition of fungus gnats. Basic and Applied Ecology 16(1), 46-53.

Sato H, Morimoto S, Hattori T. 2012 - A Thirty-Year Survey Reveals That Ecosystem Function of Fungi Predicts Phenology of Mushroom Fruiting. PLoS ONE 7(11), e49777.

Selosse MA, Martin F, Le Tacon F. 2001 - Intraspecific variation in fruiting phenology in an ectomycorrhizal Laccaria population under Douglas fir. Mycological Research 105(05), 524531.

Shorrocks B, Charlesworth P. 1980 - The distribution and abundance of the British fungal-breeding Drosophila. Ecological Entomology 5(1), 61-78.

Simmel J, Poschlod P. 2017 - Lifestyle and threat of macromycetes, and functional traits correlated with it. Mycological Progress, 1-11.

Straatsma G, Ayer F, Egli S. 2001 - Species richness, abundance, and phenology of fungal fruit bodies over 21 years in a Swiss forest plot. Mycological Research 105(5), 515-523.

Trappe JM, Luoma DL. 1992 - The ties that bind: fungi in ecosystems. In: Carrol GC, Wicklow DT. The Fungal Community: Its Organization and Role in the Ecosystem. Marcel Dekker, New York, 17-27.

Turnbull MS. 2014 - The Effects of Global Climate Change on Canadian Boreal Forest Collembola Communities, MSc. University of Western Ontario, London, Ontario. 